\title{
Organizational Structure Influence on the Level of Trust among Employees: The Case Study of "Telecom Serbia"
}

\author{
Borislav Kolarić (Corresponding author) \\ "Telecom Serbia"a.d. Beograd, IJ Sremska Mitrovica \\ 22000, Sremska Mitrovica, Stari Most 6, Serbia \\ Tel: +00381-64-6522-411Ｅ-mail: kayak@open.telekom.rs \\ Slobodan Radojčić \\ Municipality of Irig, Irig \\ 22406, Irig, Zmaj Jovina 149, Serbia \\ Tel: +00381-64-1861-287 E-mail: borcisoirig@neobee.net
}

Received: December 20, 2010 Accepted: January 14, 2011 doi:10.5430/ijba.v2n1p28

\begin{abstract}
New business approach in modern market environment imposes a fact that there is no existence without the creation of organizational structure and culture, which support the generation of innovation processes and development of knowledge management. These processes become a precondition for success or even the survival of an organization. In order for the mentioned concepts to be successfully implemented in organizational structure of an organization, the necessary precondition represents an adequate level of trust and cooperation between the employees within an organization. The purpose of the paper is the analysis of organizational design and identification of the level of employees trust and cooperation within the company "Telecom Serbia". The facts that Serbia is a country in transition, that telecommunication market in Serbia was recently liberalized with the entrance of new operators, and at the same time, the long monopolistic status of the company "Telecom Serbia", indicate the significance of subject's research and the interest of the topic. Research results have shown that present level of trust and cooperation among employees is not very high. Also, the research has pointed out some weak spots of the organizational design, which are at the same time inhibition factors in the knowledge sharing, trust and cooperation. Scientific information obtained by investigating the title topic, could be useful to the management of domestic telecommunication companies, as well as other service companies.
\end{abstract}

Keywords: Organizational structure, Trust among employees, Cooperation

\section{Introduction}

Today's turbulent market, which requires faster responses from companies, as well as strong globalization, imposes on the organizations significant transformations through finding the strategies capable to provide competitive advantage. Thus, the companies are imposed with the necessity for permanent differentiation of its products and services through continuous innovation. That implies new knowledge and ideas transformed and implemented in products, services or processes, which create value for the company. Cohen and Levinthal (1990) claim that innovation outputs mostly depend on knowledge accumulation that provides the innovators with assimilation and use of this knowledge.

In order for a company to be capable of generating innovation processes and implementation of knowledge management concept, which require free expressing of opinions and suggestions by the employees, as well as unrestricted exchange of knowledge between employees throughout the organization, the existence of the adequate level of trust between the employees is necessary.

The aim of modern business is the development of organizational structure and culture in which the knowledge is easily shared among the members of organization, both through the social and electronic network. Unlike the transfer of the explicit knowledge, there is a problem of sharing the implicit knowledge between the members of an organization, from whose level of discovery and sharing within the organization, level of its competitive advantage can largely depend.

Organization has to develop open environment in which the employees feel free to, in the atmosphere of trust, share their knowledge and use the knowledge of other people. If there is no trust in colleagues and managers among the employees, 
even besides the availability of various advanced technologies, the cooperation will not be at the appropriate level. Confidence building between the employees, as well as in the relation between the employees and managers, represents means for the success of knowledge management process.

The research results have indentified and determinated the factors of the organizational structure which had relevant impact on level trust among employees in the company. Thus, they gave relevant benefit for the future research in field of efficiency of the organizational structure, which can provide high level of trust and collaboration among employees. Scientific information obtained by investigating the title topic, besides possibility of benefit for management of domestic telecommunication companies, could be useful to the, as well as other service companies.

\section{The purpose of research}

Choice and dealing with problems concerning title topic were initiated by the current situation in the national telecommunication sector. Liberalization and deregularization of the market have influenced the apperance of more operators in the field of mobile telephony and providing ADSL services. The existence of three operators of mobile telephony, market struggle in the field of ADSL services and cable television, as well as the apperance of the new operators of fixed telephony, have implicated more rapid changes and turbulences in telecommunications sector of Serbia.

In such conditions, for each participant in telecommunications market, it is of relevant significance to create a more valuable service for the user in relation to the competition. It is followed by the existence of the possibilities for the generation of new knowledge and ideas within a company, as well as the creativity of employees within it.

Company "Telecom Serbia" passes through one of its significant periods of development. As a dominant operator in our area, it is today faced with increasing and stronger competition in all fields of providing telecommunication services. Due to this, all today's solutions related to business strategy should meet the requirements in the future in order to secure high availability of services and provide modern operating mode in all its elements. Facts that it is about a company that has been in state property until recently and that it had monopolistic status, as well as that it is characterized by strict hierarchical structure, influence the choice and focus on its organizational structure and design.

All the above-mentioned has initiated the reason and motive for investigating on the subject how much the current highly hierarchical organizatonal structure of "Telecom Serbia" supports the climate of openness, cooperation and trust among employees, as basic preconditions in the creation of the processes of innovation and knowledge management. Analysis of the relationships between employees, cooperation between individuals, as well as the services within the company, support to teamwork and multifunctional cooperation in organization, had the task to collect the information necessary and create the real image about how the today's organizational design of "Telecom Serbia" is suitable for the possibility of operating according to modern management principles.

\section{Literature review}

In literature editions, there is a consensus that the trust is an essential element of the success of an organization. Argyris (1973) believes that, if the no confidence is increasing in an organization, the individuals will only take care of themselves, before they decide and devote themselves to joint work. As a result, productivity decline will occur through the decrease of information flow and inefficient decision-making, as a consequence of it. He suggests that future organizations should ,search for enriched work, increase the openness, trust, and acceptance of risk and expression of their feelings".

Cook and Wall (1980) concluded that trust among the individuals and groups in an organization are very important and significant for a long-term stability of organization and well-being of its members. Cohenand Prusak (2001) believe that trust is an essential fluid for all social activities, allowing people to work and live together, without creating unnecessary stresses and conflicts during negotiations. Zand (1997) sees trust as willingness for discovering owns vulnerability towards other person whose behavior cannot be controlled, in the situation in which potential benefits are much smaller in relation to the potential losses if other person takes advantage of that vulnerability.

Investigations on the subject of organizational trust are often related to investigations concerning organizational and working relations. Daley and Vasu (1998) have dealt with investigations of the relations of confidence of employees towards top management. They have reached the conclusion that efficiency of work effects in a company does not only depend on the effects of training and payment levels. The relationship towards the elements of internal characteristics of business, such as benefits, recognitions and rewarding the employees, as well as work environment, show their impact in spreading the trust within the organization. External work characteristics, such as satisfaction by work, control and evaluation are also important determinants of organizational trust (Daley \& Vasu, 1998). 
Very frequent opinion is that organizational culture with a high level of sociability also implies the high level of trust. However, this does not have to be a conditioned phenomenon for the practice. On the other hand, there can be trust in some person, which does not have to be the one that we like.

Creation of trust requires a long time of building it, but it can also be destroyed. According to De Furia (1997), the benefits that an organization can have of the high level of trust include: stimulation of innovations; movement towards high emotional stability; facilitation of acceptance and openness for free expression and encouragement for risk acceptance. As opposed to the above-mentioned, the consequences of the low level of trust imply: lack of understanding when it comes to values and motives of other employees; non-efficient communication; reduced possibility of recognizing and accepting good ideas; increasing the efforts for obtaining relevant information; increasing the control mechanisms - self-control is replaced by external control; increase of rejection, defensive and hostility; delayed implementation of activities and projects; mentality „,victory-victory“ is replaced by „,victory-defeat“ (De Furia,1997).

People cannot require for the others in organization to have trust in them. It needs to be earned and developed during the time (Fairholm, 1994). Expecting and requiring trust from the others often leads to the zone of cold behavior, because people mostly believe in other people on the basis of moral characteristics. This type of behavior can lead to the environment of no confidence, rather than mutual confidence.

Organizational trust is not a simple concept for understanding. Examination of trust requires the consideration of numerous factors. According to Mishra (1996) and his model of organizational trust, there are a few dimensions of organizational trust: competence, openness and reliability. Latest studies have discovered another factor that is of the same significance for consideration as the four mentioned, and that is identification, i.e. measurement of the level of individual relations of employees towards common objectives, norms, values and beliefs, joint with organizational culture. (Shockley - Zalabak, Ellis \& Winograd, 2000).

Savage (1982) presents a few important elements characteristic for the organizations where the trust level is low, or there isn't any: the atmosphere is often quiet with the low level of energy and engagement; there are no conflicts, anyone who impairs the system or expresses dissatisfaction is punished or fired; each change is observed with doubt and alarm, managing is from top to bottom, status is important, decisions are verified through the chain of commanding, people feel as if they are incarcerated within their work.

On the other hand, there is a range of behavior typical for organizations of high performances. According to Phillips (1997), organizations of high performances contain five common elements: all those who have leaders who understand the value of accepting work tasks in current operating; leaders are visionary, which clearly articulate their visions; they believe in sharing the wealth with employees and they realize it; they understand the values of intellectual capital and invest in it; they understand the values of loyalty and look for the way to support and develop it.

Organizational climate of trust allows the employees to express their ideas, feelings and mutual learning. Organization without trust can make a negative position with people, which will prevent them in learning. Development of trust occurs in the situations where the individuals have freedom to express themselves in their daily tasks, without unnecessary control, monitoring and supervision (Fairholm, 1994). Supporting those freedoms will also develop the environment of high trust between the employees and management.

According to Sonnenburg (1994), high confidence level within an organization implies: reducing discord and conflicts between the employees; mutual obligation of people; productivity increase; stimulation of development; improving the morale of employees; reducing the abstinence of employees; creating the environment where the innovations can be developed and advanced.

During the recent years, it is very much spoken about organizational form. Such organizations are focused on trust, cooperation, teamwork and they reject typical individual approaches. They are very often referred to as organizations of high performances, which tend to take what is best from individuals and create extraordinary abilities for transferring the valuable results to all the employees in organization (Dalton, 2000). Such organizations create goods and services with a lot greater quality in relation to traditional hierarchical organizations (Jordan, 1999). With such identity, organizations of high performances, apparently take over the position from traditional hierarchical organizations.

\section{Research methodology}

According to the theoretical frameworks about the significance of high confidence in an organization in modern business, and simultaneously taking into account the movements in telecommunication market in Serbia, the aim of research consisted of examining how much the today's organizational design and structure of "Telecom Serbia" are appropriate for creation and maintaining of the high level of trust between the employees throughout this company. 
Designed like this, the aim of research was focused on many tasks:

- Determining the level of employees' mutual trust within an organization;

- Determining the confidence level between the employees and managers within an organization;

- Determining the level of information and knowledge exchange between employees within an organization;

- Determining the quality of cooperation between the services within an organization;

- Examining how much the teamwork is supported within an organization.

\subsection{Sample, research method and the applied method of statistical analysis of data}

Research was done by the questionnaire method among the employees of "Telecom Serbia" in the territory of the region of Vojvodina, which can be classified as a representative sample of company according to many criteria. The sample has included 220 respondents, namely $15 \%$ of the total number of employees on the mentioned territory. In order to obtain a more reliable and precise image on the real situation in relation to the mentioned research subjects, the respondents are divided into two criteria groups - employees and their managers. In that way, apart from obtaining the information in relation to the opinion and attitudes of employees as a group, the analysis of how different or similar are the employees' responses in relation to managers is provided.

Validation of questionnaire and data was carried out through more statistical methods and tests:

- Application of SPSS program was aimed at determining and displaying the frequencies and cross tabulation.

- MANOVOM (multivariate analysis of variance) analysis it was examined whether in the group as a whole there are differences in responses of the two criteria groups observed.

- By ANOVOM analysis (unvaried analysis of variance), differences in responses of the two criteria groups were examined for each question.

- The discriminate analysis has identified difference and distance among two criteria groups.

- Coefficient of discrimination existing differences obtained in previous analysis is expressed quantitatively, which was a prerequisite for the formation of the most frequent responses by relevant issues.

Considering that we talking about categorical data, before statistical data summarization, it was made a scaling of data, as a help for realization and application MANOVA, ANOVA, discriminate analysis, and coefficient of discrimination. These results were tested through discriminate analysis and coefficient of discrimination, and they are much more powered then simply testing the reliability of questionnaire. The resultants tested on that way, can give exact measure of difference and distance among two criteria groups.

\section{Research results}

\subsection{Trust and exchange of knowledge}

As it was already mentioned, for the success of the programme of knowledge management, the climate of openness, trust and cooperation among the employees is of crucial significance. In order for knowledge to be spread, exchanged and that it can freely flow within an organization, it is necessary that the employees feel free, that they have no fear that sharing their knowledge will bring them to a worse business position. On the contrary, instead of considering the „revealing" of their skills and knowledge as a potential loss of their powers in organization, the employees could recognize the knowledge exchange as a possibility of their personal advancement and improvement, as well as the improvement of entire organization.

Research results have shown that $67 \%$ of employees consider that knowledge and information exchange among the employees is present to a small degree, $2 \%$ has the attitude that it does not exist, while $31 \%$ believes that knowledge exchange in organization is at satisfactory level:

$<$ Figure 1 about here $>$

In addition, it was important to analyze the data about with whom are the employees willing to exchange their knowledge:

$<$ Figure 2 about here $>$

Hence, the major part of employees $(53 \%)$ has declared that they share their knowledge within their departments, i.e. services, while $33 \%$ expand this activity onto the entire organization.

As for the confidence, $55 \%$ of respondents have partial trust in their colleagues, $44 \%$ have expressed a complete trust, while $1 \%$ is completely no confidential.

$<$ Figure 3 about here $>$ 
Somewhat different attitudes and opinions, the employees had in relation to the trust in their superiors: $47 \%$ of them has expressed a complete trust, $47 \%$ partial trust, and $6 \%$ have expressed an attitude of nonconfidence.

Presented data in this part of the paper point out that the existing climate of trust is at a mediocre level, with poor frequention of information and knowledge exchange, which mostly develop within individual departments, and all this does not represent an adequate potential that is required by successful implementation of knowledge management programme.

\subsection{Organizational support to the cooperation and teamwork}

Modern business principles negate hierarchical structures, as well as traditional inner organizational divisions into departments, services, sectors. Their place is increasingly being taken by business processes with teamwork within entire organization. For those reasons, it was very interesting to examine the relations within the wholes of enterprises.

Technical service as a carrier of innovation and development of the company, on one hand, and as well as commercial service, effectivity factor of services selling on the other hand, make a "competence core“ of the company, by which they have imposed a logic in examining the employees' relations precisely between these two relevant organizational wholes. The employed in "Telecom Serbia", namely $87 \%$ of respondents believe that the firms' success largely depends on the quality of cooperation between its constituent parts, as well as that business activities of an organization require their narrow cooperation and sinchronization.

However, considering their opinions and attitudes concerning the previous level of quality of cooperation and information exchange between two mentioned organizational units, it can be seen that merely $3 \%$ of respondents considers that these relations are at high level, while $46 \%$ believes that this cooperation is at the low level.

$<$ Figure 4 about here $>$

Cooperation and teamwork have a very important role in innovation generation and knowledge exchange. Multifunctional teams can be especially good in the creation of new knowledge and idea that is innovative and practical. Such teams bring various skills and knowledge, and also the approach to the problems from various perspectives, by which the possibility for openning a large number of creative solutions to the problems is created.

In the analysis of employees' attitudes concerning the support to the cooperation and teamwork from the part of top management within the organization, it can be seen that merely $15 \%$ of respondents consider that such relations exist within limits of satisfactory level, while $37 \%$ of them do not have a positive opinion regarding the same question:

$<$ Figure 5 about here $>$

\subsection{Characteristics of responses of the two criteria groups}

In order to examine whether there are any differences in the responses of the employees and their managers to the analyzed questions, as well as how much the responses vary, the multivariate analysis of variance was applied:

\section{$<$ Table 1 about here $>$}

By MANOVOM analysis, all the questions are observed as a unique whole and the objective is to determine whether there are any differences in responses of the two observed criteria groups in that whole. This analysis indicates the existence or non-existence of the difference (YES or NO). If the result obtained is smaller than $0,05-$ there is a significant difference; $0,05-0,1$ - there is a difference with an increased risk of existence; and if the result is larger than 0,1 - there is no statistically significant difference. As the obtained result is in the range between 0,05 and 0,1 , i.e. $p=$ 0,06 , it is determined that in the responses between two criteria groups there is a difference with an increased level of existence.

In order to identify the questions in case of which there is a determined difference, the unvaried analysis of variance was applied, by which each question is analyzed separately according to the same parameters as in case of MANOVA analysis.

$<$ Table 2 about here $>$

The data shown in the Table 2. indicate that in case of the three questions, there is a difference in responses of employees and managers, but those differences are in the domain of difference with an increased risk of existence.

In order to determine the size differences in the given answers, the discriminate analysis is applied.

$<$ Table 3 about here $>$

From the given Table 3., it can be seen that the largest difference in responses is in the opinions regarding the support to the cooperation and teamwork (coeff. 0,037), as well as in the attitudes concerning the trust climate (coeff. 0.030). On the other hand, the greatest similarities in responses of employees and managers are identified with the responses related 
to knowledge sharing within the organization (coeff. 0,001), as well as responses related to the opinion about the knowledge exchange level within the organization (coeff. 0,003).

Data and parameters, obtained through the coefficient of discrimination, have served as basis for determining the most frequent responses to the belonging questions in both criteria groups.

\footnotetext{
$<$ Table 4 about here $>$
}

Based on the data shown in Table 4., it can be seen that in case of the questions, which in their responses have the greatest difference in attitudes of two criteria groups - "support to cooperation and teamwork", the most frequent answer with managers was "to a small degree", while with employees, the response "does not exist" prevailed. As opposed to this, in the responses to the question about "knowledge exchange level", as well as "sharing the knowledge within organization", the responses of employees were largely the same.

\section{Discussion}

Literature overview has indicated the significance of organizational trust and high level of cooperation between the employees, in today's conditions of modern business. Organizational climate of trust allows the employees to express their ideas and feelings and common learning. Organization without trust can create an unfavorable position with people that will prevent them from learning. Development of trust occurs in situations where the individuals have freedom of expression in their daily tasks, without unnecessary control, monitoring and supervision (Fairholm, 1994). Support to such freedoms will also develop an environment of high trust between employees and management.

By analyzing the processed data, it can be seen that even $67 \%$ of respondents believes that knowledge and information exchange within "Telecom Serbia" are present to a small degree. By further observation, it is seen that this poor exchange of knowledge occurs largely with colleague within department or service (53\%). The consequence of it can certainly be found in the results related to the attitudes and opinions of employees in relation to the trust in colleagues and managers within the entire organization. Namely, $44 \%$ of respondents has a complete trust in their colleagues, while somewhat higher percentage of trust is expressed towards managers (47\%). From data mentioned, it can be concluded that the trust level, as well as openness of employees for cooperation and knowledge exchange are of insufficient capacity that is required by successful implementation of the processes of innovation and knowledge management.

The quality level of cooperation between services is closely related to the level of trust and knowledge and information exchange. Results obtained by this question point out that $47 \%$ of respondents sees the quality of cooperation between services and departments within company as satisfactory, while $46 \%$ considers that cooperation level is low. The results mentioned are partially the consequence of the type of organizational structure, which favorite's classical hierarchical and centralized system. All of the above-mentioned is confirmed in the results obtained in the analysis of organizational support to cooperation and teamwork, where $43 \%$ of respondents believe that it is expressed to a small degree, and $37 \%$ of respondents believes that it does not exist at all.

Observing the answers of respondents through two criteria groups, - employees and managers, after applying discriminated analysis, it can be seen that in the large number of questions, both criteria groups have slight differences, namely they have a lot of similarities in their opinions and attitudes. The largest disagreements in responses of employees and managers were with questions in relation to the cooperation and support to teamwork. The employees believe that such support does not exist at all, while the managers believe that it exists, although it is expressed to a small degree. Representatives of both criteria groups share their knowledge only within departments or services, and it logically results in the same response that knowledge exchange and cooperation throughout the organization are at the low level.

Similarities in responses of employees and managers provide another confirmation of the negative effect of hierarchical organizational structure. It leaves the complete decision-making to the top management, without leaving a space to the low level managers for participating in decision-making and autonomy in realization of work tasks. Precisely for those reasons, most responses of managers are very close to the attitudes of employees. Both managers and employees are deprived of the delegation of tasks and autonomy in work processes. Work tasks are focused on performance within services and departments with a very small stress on multifunctional cooperation within the enterprise.

High hierarchical chain, with clearly defined departments and services leaves a little space for multifunctional cooperation, both between individuals and between services and departments. Such organizational design does not provide any support to the open cooperation and strengthening of trust within organization, but it points out that traditional hierarchical structure has no real development of organization that will be inclined to the employees by its functional structure, because the levels of trust and cooperation are very small.

\section{Conclusion}

The aim of the research presented was to determine the relations between organizational structure and work relations between employees within the company "Telecom Srebia". Research results have clearly identified the type of influence, which the traditional hierarchical structure has on the trust level between employees, and their willingness for open cooperation. 
Literature related to the implementation of knowledge management, as well as innovation processes, indicates that certain factors such as climate of trust and openness, mutual cooperation of employees, as well as a more flat organizational structure, play a very important role in the success of implementation of knowledge management and innovation processes. The organizations of high performances have great trust between associates, as well as between employees and management, because the employees have a high degree of empowerment in relation to business processes. This requires that management has trust in the employees and their abilities to complete the trusted tasks entirely and in appropriate way. Organizational climate of trust enables the employees to express their creations, innovations and ideas, using each other as resources and learning together. Without trust, the employees have a tendency of „,losing“ and keeping their skills and ideas to themselves, rather than sharing them with the others, and all of that slows down the creativity of entire organization. (Jordan, 1999).

Traditional corporative environment, with its hierarchical structure, will not support the cooperation and knowledge exchange, which are by far more superior in organizations that encourage autonomy, respect, trust and self-control as opposed to strict supervisions, rigid business constraints and direct control (Dalton, 2000.).

Employees in all organizations want to work in the environment of trust and respect, where their feelings, ideas and creativity create a true contribution to organizational efforts and objectives. They want to have an opportunity to show the management their abilities to assume responsibilities for assigned tasks and to realize the same with their creativity and teamwork.

Apart from the awareness of the fact that knowledge management concept and innovation processes in Serbia are slightly known and applicable, top management of the company "Telecom Serbia" should seriously deal with current organizational structure and culture. Considering that this company is largely involved in the market game in the field of mobile telephony, ADSL services and digital television, as well as that there are several new operators of fixed telephony that appeared this year, and in order to preserve its leading position and remain successful, it needs to incorporate modern business principles. In tendency to create an organization of high performances, management of the company has to understand that in the organization there is no more existence for linear structure, which has to give its place to flat organizational structure. In that way, the door for creation of trust and satisfaction with work is open.

In order for organizational design of some organization to become adaptible for challenges imposed by modern market environment, it is necessary to initiate certain organizational changes as well as to set the following principles as basic (Harman \& Brelade, 2000) :

- $\quad$ High level of autonomy for individuals;

- $\quad$ Respecting the skills, knowledge and talents;

- $\quad$ Reducing bureaucratic policy and avoiding forbidden questions;

- $\quad$ Encouraging the policy of sharing;

- $\quad$ Respecting the employees that begin to feel valuable;

- High level of involvement when making decisions;

- $\quad$ The efforts to make the job stimulating and more meaningful;

- $\quad$ Minimal, but efficient administration;

- Cooperation instead of competition.

\section{References}

Argryis C. (1973). On Organizations of the Future, Beverly Hills: Sage

Cohen D. \& Prusak L. (2001). In Good Company: How Social Capital Makes Organizations Work, Harvard Business School Press.

Cohen W.M. \& Levinthal, D.A. (1990). Absorptive Capacity: A New Perspective on Learning and Innovation, Administrative Science Quarterly, 35, pp 123-138. doi:10.2307/2393553, http://dx.doi.org/10.2307/2393553

Cook J. \& Wall T. (1980). New Work Attitude Measures of Trust, organizational commitment and personal need no fulfillment, Journal of Occupational Psychology, 53, pp 39-52.

Daley D.M. \& Vasu M.L (1998). Fosternig Organizational Trust in North Carolina, The pivotal role of administrators and political leaders, Administration and Society, 30 (1), 62-84. doi:10.1177/009539979803000105, http://dx.doi.org/10.1177/009539979803000105

Dalton D. (2000). Understanding High Perfomance Organizations. Security, 37, pp 69.

Dammen J.K. (2001). The Effect of Organizational Structure on Employee trust and Job Satisfaction, Graduate School University of Wisconsin-Stout. 
De Furia G.L. (1997). Facilitators Guide to the Interpersonal Trust Surveys, Pfeiffer\&Co.

Fairholm G.W. (1994). Leadership and the Culture of Trust, Westport, CT: Praeger.

Glover C. \& Smethurst S. (2003). Great Ideas Wanted, People Management Online, (April 8), retrieved from www.peoplemanagement.co.uk.

Harman C. \& Brelade S. (2000). Knowledge Management and the Role of HR. Securing Competitive Advantage in the Knowledge Economy, Prentice Hall.

Jordan S.A. (1999). Innovative Cultures + Empowered Employees $=$ High Perfomanse Organizations, Public Productivity and management Review, 23, pp 109-115. doi:10.2307/3380798, http://dx.doi.org/10.2307/3380798

McCauley D.P. \& Kuhnert K.W. (1992). A Theoretical Review and Empirical Investigation of Employee Trust in Management, Public Administration Quarterly, 16, pp 265-285.

Pfeffer J. (1998). The Human Equation, Boston, MA: Harvard Business School Press.

Phillips C.J. (1997). Do you Trust me? Executive Excellence, 14, pp 7-10.

Savage D. (1982). Trust as a Productivity Management Tool, Training and Development Journal, 54-57.

Shockley-Zalabak P., Ellis K. \& Winograd G. (2000), Organizational Trust: What it Mean and Why it Matters. Organizational Development Journal, 18, pp 35-48.

Sonnenburg F.K. (1994). Managing With a Conscience, New York: McGraw-Hill.

Zand D.E. (1997). The Leadership Triad - Knowledge, Trust and Power, Oxford University Press.

Table 1. Significance of the difference between respondents

\begin{tabular}{|l|c|c|c|}
\hline & $\mathbf{n}$ & $\mathbf{F}$ & $\mathbf{p}$ \\
\hline MANOVA & 10 & 4.379 & 0.03 \\
\hline
\end{tabular}

Table 2. Significance of the difference between the respondents by the given questions

\begin{tabular}{|l|c|c|c|c|}
\hline & $\chi$ & $\mathrm{R}$ & $\mathrm{F}$ & $\mathrm{p}$ \\
\hline Knowledge exchange level & 0.146 & 0.148 & 1.982 & 0.163 \\
\hline Sharing the knowledge within organization & 0.123 & 0.124 & 1.397 & 0.240 \\
\hline Attitudes concerning the confidence climate & 0.219 & 0.224 & 4.704 & 0.033 \\
\hline Quality level of cooperation between departments & 0.199 & 0.203 & 3.817 & 0.054 \\
\hline Support to cooperation and teamwork & 0.229 & 0.235 & 5.204 & 0.025 \\
\hline
\end{tabular}

Table 3. Coefficient of discrimination, between respondents in relation to the answers

\begin{tabular}{|l|c|}
\hline & Coefficient of discrimination \\
\hline Support to cooperation and teamwork & 0.037 \\
\hline Attitudes concerning the confidence climate & 0.030 \\
\hline Quality level of cooperation between departments & 0.024 \\
\hline Knowledge exchange level & 0.003 \\
\hline Sharing the knowledge within organization & 0.001 \\
\hline
\end{tabular}


Table 4. Characteristics of the respondents in relation to the answers

\begin{tabular}{|l|c|c|c|}
\hline & c. of discr. & managers & employees \\
\hline $\begin{array}{l}\text { Support to cooperation and } \\
\text { teamwork }\end{array}$ & 0.037 & To a samll degree & Does not exist \\
\hline $\begin{array}{l}\text { Attitudes in relation to confidence } \\
\text { in colleagues }\end{array}$ & 0.030 & Completely & Partially \\
\hline $\begin{array}{l}\text { Quality level of cooperation } \\
\text { between departments }\end{array}$ & 0.024 & Satisfactory level & Low level \\
\hline Knowledge exchange level & 0.003 & To a small degree & To a small degree \\
\hline $\begin{array}{l}\text { Sharing the knowledge within } \\
\text { organization }\end{array}$ & 0.001 & $\begin{array}{l}\text { With a colleague } \\
\text { within department }\end{array}$ & $\begin{array}{l}\text { With a colleague } \\
\text { within department }\end{array}$ \\
\hline
\end{tabular}

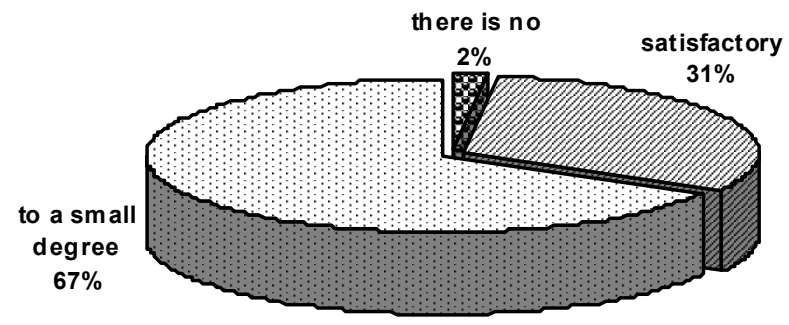

Figure 1. Level of information exchange

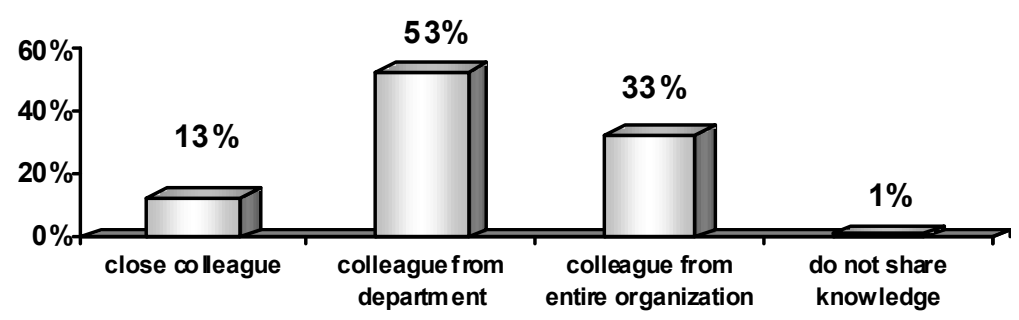

Figure 2. Sharing the knowledge within organization 


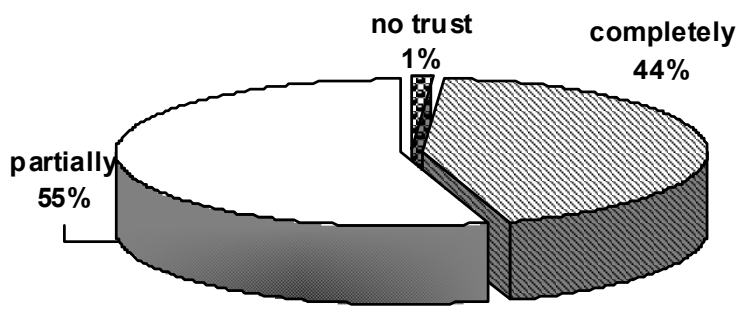

Figure 3. Attitudes in relation to the trust climate

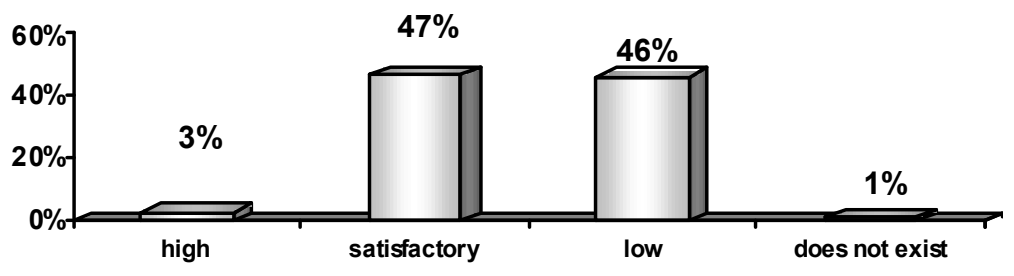

Figure 4. Quality level of cooperation between departments

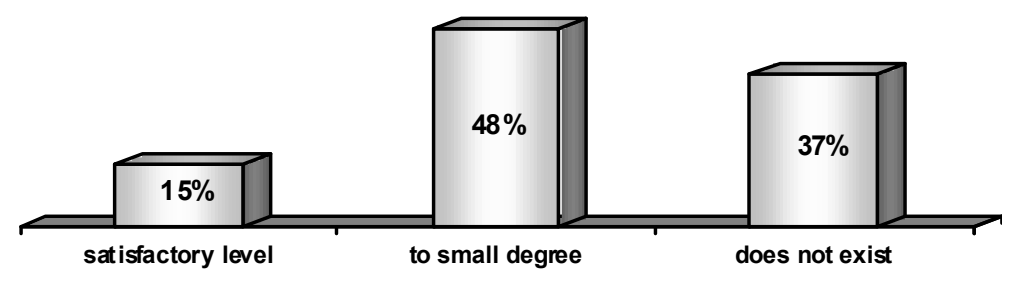

Figure 5. Support to cooperation and teamwork 